\title{
Theoretical aspects of levothyroxine: bioavailability and drug stability
}

\begin{abstract}
Hypothyroidism is a state of thyroid hypofunction due to different causes and produces as a final state an insufficient synthesis of thyroid hormones. Worldwide, its prevalence is between $1 \%$ and $4 \%$. Levothyroxine is the best treatment in hypothyroidism but is a drug with stability problems reported in the literature. The bioequivalence studies are required to establish pharmaceutical equivalents between the different brands of Levothyroxine.
\end{abstract}

Keywords: levothyroxin, bioavailability, drug stability, hypothyroidism
Volume 5 Issue I - 2018

\author{
Sánchez JC \\ Department of Pharmaceutical Chemistry, Universidad de \\ Ciencias Aplicadas y Ambientales, Colombia
}

\begin{abstract}
Correspondence: Sanchez JC, Department of Medicine, Departament of Pharmaceutical Chemistry, Universidad de Ciencias Aplicadas y Ambientales, I I I 166, Bogotá, Colombia, Tel +57-1-6684700,Email juliasanchez@udca.edu.co
\end{abstract}

Received: January 27, 2018 | Published: February 09, 2018
Abbreviations: TSH, thyroid stimulating hormone; mIU/L, milli-international units per liter; $\mathrm{ml}$, milliliter; T4, thyroxine; T3, triiodothyronine; ${ }^{\circ} \mathrm{C}$, celsius temperature

\section{Introduction}

Hypothyroidism is a state of thyroid hypofunction due to different causes and produces as a final state an insufficient synthesis of thyroid hormones. Worldwide, its prevalence is between $1 \%$ and $4 \% .{ }^{1}$ Because the symptoms of the disease are very nonspecific, the definition of the disease is based on the alteration of the hormone levels measured in serum. The diagnosis is based on the demonstration of high TSH levels $(>10 \mathrm{mUl} / \mathrm{ml}){ }^{2,3}$ Uncontrolled patients frequently present symptoms related to hypothyroidism, including comatose myxedema, which is the major complication of hypothyroidism. ${ }^{4,3}$ Levothyroxine is the best treatment in hypothyroidism and has a good correlation with adequate levels of TSH and improves the cognitive level clinically compared to thyroxine plus triiodothyronine therapy. ${ }^{1}$

However, Levothyroxine is a drug with stability problems as reported in the literature and oral preparations can be affected by physical factors. It is a medicine with narrow therapeutic index and may have problems of bioavailability. Sometimes bioequivalence studies are required to establish pharmaceutical equivalents between the different brands of Levothyroxine. To expand on this information, the following review is presented below.

\section{Discussion}

The thyroid gland normally secretes 10 times more T4 (levothyroxine or thyroxine) than T3 (triiodothyronine), but the main active form of thyroid hormone is T3 that is obtained in $80 \%$ from the peripheral deiodination of $\mathrm{T} 4$, by 5 '-deiodinase type 1 (hepatic and renal) and the rest by active type 2 deiodinase present in central nervous system, pituitary, adipose tissue and placenta. ${ }^{5}$ The effects of thyroid hormones are mediated by the binding of hormones to specific nuclear receptors that correspond to transcription factors, in the case of T3; this hormone has an affinity 10 times higher than $\mathrm{t} 4$ by these receptors, which explains that has greater biological activity. ${ }^{5}$ Levothyroxine transforms into T3 in peripheral organs and, like the endogenous hormone, develops its effect at the level of T3 receptors; its main pharmacological effect is to increase the metabolic rate of body tissues, as well as the regulation of cell growth and differentiation. Levothyroxine is the best treatment in hypothyroidism compared to thyroxine plus triiodothyronine therapy. ${ }^{6}$ Levothyroxine sodium is commercially available for oral administration and in the form of a lyophilized powder for injection of parenteral administration. The medicine available in the market is prepared synthetically.

Sodium levothyroxine is stable in dry air, but may acquire a light pink colour with exposure to light. The commercially available preparations of levothyroxine sodium should be stored in airtight containers, resistant to light; since it is unstable in the presence of light, heat, air and humidity. ${ }^{8}$ Recommended storage temperatures may vary depending on the specific manufacturer and the preparation. In some cases, the tablets of the drug have been unstable, even at room temperature, and storage at temperatures of $8-15^{\circ} \mathrm{C}$ allowed maintaining the potency.

In 1997, the United States drug regulatory agency (FDA) determined that stability and pharmacological potency problems have existed during oral preparations for levothyroxine sodium, and this type of problems could result in serious health consequences due to of the incompatibility of the potency of medications. ${ }^{9-11}$ in many of the oral preparations of levothyroxine sodium that were commercially available, the potency could not be maintained for at least 2 years, so it was suggested that this preservation time may not be appropriate for these preparations due to accelerated degradation by a variety of factors (for example, light, temperature, air, humidity).

In addition, some excipients contained in oral preparations for levothyroxine sodium may accelerate this degradation; results of some studies indicate that in the stability of levotiroxina sodium there is a biphasic degradation, with an accelerated rate in the initial degradation (that depends on the temperature), followed by a slow phase. To compensate for the rapid initial rate of degradation, some manufacturers use excessive amounts of active ingredient, which could lead to superpower. ${ }^{8}$ In patients with diminished or absent thyroid function, the uniform potency and bioavailability of sodium levothyroxine tablets is very important, since hypothyroidism or hyperthyroidism may result from the administration of preparations with less or more than the required potency and bioavailability. 
The FDA between 1987 and 1994 received 58 reports of adverse reactions apparently associated with the irregular potency of sodium levothyroxine preparations. Due to the reported potency and stability problems, the FDA announced in 1997 that oral preparations containing levothyroxine sodium would be considered as a new drug and manufacturers would have to submit a new drug application (NDA) to the FDA before 14 August 2000 and then an extension before 14 August 2001. ${ }^{8,12}$

The oral preparations for levothyroxine sodium that did not have an approved application before this date had to leave the distribution of their products from that moment. All oral preparations of sodium levothyroxine commercially available in the USA, before August 14, 2003, they had been approved by the FDA as safe and effective for their use. ${ }^{7}$ Other oral preparations have already been approved by the FDA because they have been evaluated and considered to be therapeutically equivalent, but even so stability problems can still be found with oral preparations of levothyroxine depending on storage conditions. $^{13}$

\section{Conclusion}

The FDA talks about therapeutic equivalents when the difference between the maximum concentrations are between $80-125 \%$ of the average, with $90 \%$ confidence intervals and with a difference between the areas under the curve very small (5\% or less) . Even so, the FDA has found difficulties to determine equivalence in different products. Additionally, oral preparations for Levothyroxine sodium cannot sustain potency throughout its shelf life, and the amount of active ingredient varies from batch to batch.

As a result of these stability problems the potency of a given preparation cannot be assured, even when the same brand of Levothyroxine sodium is used in the oral preparation. ${ }^{8}$ Bioequivalence studies are required for drugs with narrow therapeutic margin to ensure conditions of adequate bioavailability in the different commercial brands of levothyroxine. ${ }^{14}$

\section{Acknowledgements}

None.

\section{Conflict of interest}

The author declares no conflict of interest.

\section{References}

1. Canaris GJ, Manowitz NR, Major GM, et al. The Colorado thyroid disease prevalence study. Arch Intern Med. 2000;160(4):526-534.

2. Díez JJ, Iglesias P. Spontaneous subclinical hypothyroidism in patients older than 55 years: an analysis of natural course and risk factors for the development of overt thyroid failure. J Clin Endocrinol Metab. 2004;89(10):4890-4897.

3. Lazarus JH, Premawardhana LD. Screening for thyroid disease in pregnancy. J Clin Pathol. 2005;58(5):449-452.

4. Danese MD, Powe NR, Sawin CT, et al. Screening for mild thyroid failure at the periodic health examination: a decision and cost-effectiveness analysis. JAMA. 1996;276(4):285-292.

5. Isaza C, Isaza G, Sources J, et al. Fundamentals of Pharmacology in Therapeutics. Chapter. 2014;9:311-313.

6. Ma C, Xie J, Huang X, et al. Thyroxine alone or thyroxine plus triiodothyronine replacement therapy for hypothyroidism. Nucl Med Commun. 2009;30(8):586-593.

7. Goodman Louis S, Gilman Alfred, Hardman Joel G, et al. Goodman and Gilman's the pharmacological basis of therapeutics. 9th ed. New York: McGraw-Hill; 1996. 1905 p.

8. Prescription Drug products; levothyroxine sodium. US Food and Drug Administration, Notice of proposed rulemaking, Docket No. $97 \mathrm{~N}-0314$. Fed Regist. 1997;62(157):43535-43538.

9. Shroff AP, Jones JK. Standards for levothyroxine preparations. JAMA. 1980;244(7):658-659.

10. Stoffer SS, Szpunar WE. Potency of brand name and generic levothyroxine products. JAMA. 1980;244(15):1704-1705.

11. Ramos-Gabatin A, Jacobson JM, Young RL. In vivo comparison of levothyroxine preparations. JAMA. 1982;247(2):203-205.

12. Guidance for industry: Levothyroxine sodium products enforcement of August 14, 2001, compliance date and submission of new applications. US Food and Drug Administration Center for Drug Evaluation and Research. New York, USA; 2018. p. 1-9.

13. Thyroid experts warn of clinically important differences in potency of FDA-approved levothyroxine products. The American Thyroid Association. USA; 2018.

14. Castillo JS, Gutiérrez JJL. Levothyroxine treatment failure in the management of hypothyroidism in a health institution in Bogotá, DC An analytical study of prevalence. Rev Colomb Cienc Quim Farm. 2015;44(1):16-33. 